\title{
Análisis geográfico de problemas ambientales urbanos Caso: geocorredor río Consota, municipio de Pereira (Risaralda)*
}

\author{
Urban Environmental Problems' Geographical Analysis. \\ Case: Consota River's Geocorridor, \\ Pereira Municipality, Department of Risaralda
}

Jorge Andrés Rivera Pabón**

\section{Resumen}

Se expone una propuesta de análisis de problemas ambientales urbanos desde la perspectiva geográfica; para tal fin se toma como espacio objeto de estudio el geocorredor del río Consota, en el municipio de Pereira. El análisis busca reconocer los factores y relaciones que han incidido en la dinámica ambiental resultante de la territorialización y ocupación espacial de asentamientos humanos. De esta forma, se incorporan las causas sociales, económicas, políticas, culturales y biofísicas determinantes en la transformación y degradación ambiental. Igualmente, el análisis posibilita superar la gestión ambiental, restringida tradicionalmente a propuestas desde enfoques ingenieriles (civil, sanitaria, ambiental) y de la arquitectura.

Fragmento de la tesis de magíster titulada "Análisis geográfico de la transformación y degradación ambiental en el tramo urbano del corredor del río Consota, Pereira, 1983-2003".

** Administrador Ambiental, Universidad Tecnológica de Pereira. Magíster en Geografía con énfasis en Ordenamiento Territorial, EPG, convenio UPTC-IGAC. Profesor del Departamento de Historia y Geografía de la Universidad de Caldas. Correo e.: andresrive@yahoo.com 
Palabras clave: Degradación y transformación ambiental, Fragmentación, Erosión, Contaminación hídrica, Relación sociedad naturaleza, Territorialización, Espacio geográfico, Paisaje, Geocorredor, Gestión ambiental.

\section{Abstract}

An urban environmental problems' proposed analysis is stated, from the geographical perspective. For this end, a geographical corridor objective study of the river Consota in the Pereira municipality, is assumed. The analysis pretends to recognize the factors and relationships that have impacted in the environmental dynamics resultant from the human settlements' territorialization and space occupation. By this mean, the decisive social, economic, political, cultural and biophysical causes in the transformation and environmental degradation are incorporated. Equally, the analysis facilitates to overcome the traditional environmental management, restricted to proposals from the engineering and the architectural focuses (civil, sanitary and environmental).

Key words: Degradation and Environmental Transformation, Fragmenta tion, Erosive, Hydrological Contamination, Society-Nature Relationship, Territorializing, Geographical Space, Landscape, Geocorridor, Environmental Administration.

254 Jorge Andrés Rivera Pabón 


\section{Introducción}

Con el análisis geográfico de la transformación y degradación ambiental en el tramo urbano del corredor río Consota (Pereira: barrios La Dulcera, La Platanera, Hamburgo, El Poblado I y El Dorado) se busca reconocer y entender las fuerzas condicionantes, políticas, económicas, culturales y sociales, que han venido actuando en su territorialización ${ }^{\mathbf{1}}$. Para tal efecto, el análisis se concentra en los cambios ocurridos entre 1983 y 2003, periodo de aceleración de la inmigración y expansión más reciente de la ciudad de Pereira, particularmente del establecimiento progresivo de asentamientos humanos en el tramo urbano de la cuenca hidrográfica del río Consota.

Efectivamente, se intenta construir un modelo de análisis territorial ${ }^{2}$ fundamentado en el acervo epistemológico, teórico y metodológico de la discipli- na geográfica, que incorpora tanto las ciencias sociales como las naturales. De esta manera, al tradicional y restringido modelo de los estudios ambientales, circunscritos al medio natural, se incorporan elementos conceptuales procedentes de las ciencias sociales (geografía humana, antropología, economía, sociología, historia, psicología), a los cuales se asigna un énfasis dentro del análisis, con el propósito de encauzar una visión más coherente con la naturaleza del objeto de estudio ${ }^{3}$.

Por esta razón, con base en la perspectiva de la territorialización, se desarrolla de manera consciente una particular combinación de métodos etnográficos (que incluyen técnicas cualitativas como la observación participativa, las entrevistas semiestructuradas e informales y las historias de vida, entre otras) con técnicas cuantitativas convencionales de análisis

Se entiende por territorialización el proceso de ocupación y apropiación de un espacio geográfico por un grupo humano, el cual está mediado por relaciones de poder, dominio y pertenencia. La territorialización involucra procesos sociales consensuados (ej.: comunidades residentes en áreas planificadas) o conflictivos (ej.: ocupación de áreas por procesos de invasión de comunidades desplazadas) de carácter gradual o abrupto. Expresa a su vez un nivel de cohesión social que permite reconocer la existencia individual o grupal vinculada íntimamente con el territorio. Durante el proceso de territorialización se transforma el medio habitado, de tal manera que se generan impactos ambientales sobre él.

2 Con el análisis territorial de un problema ambiental se intenta comprender cómo se origina, produce y evoluciona en el tiempo, a partir del reconocimiento de los factores socio-naturales involucrados en su ocurrencia; en otras palabras, es el análisis del proceso de territorialización de un grupo humano y las consecuencias ambientales resultantes. Este análisis territorial se diferencia de un análisis espacial, ya que el segundo se basa, generalmente, en la "espacialización" del fenómeno (erosión, deslizamiento, inundación, poblamiento, etc.), concentrándose más en el uso instrumental de la geometría para expresar su "configuración espacial", que en la explicación de las relaciones causales entre los procesos sociales (económicos, políticos, culturales) y los efectos en el medio o hábitat.

3 La incorporación y mayor relevancia de las ciencias sociales dentro del análisis territorial y la gestión ambiental permitirá abrir el espectro de la discusión en torno a los factores y bases sociales del cambio espacial-territorial y su incidencia en los conflictos ambientales. 
espacial (que incluyen el análisis de datos censales, el análisis fisiográfico con base en la ciencia del paisaje y la aplicación de las metodologías comprensivas propuestas por la ecología del paisaje).

El análisis geográfico territorial explora, por lo demás, distintas luces y caminos de entendimiento de los problemas ambientales urbanos, en tanto hace énfasis primordialmente en las causas que los originan y no exclusivamente en los fenómenos y eventos "naturales" que los evidencian. Es así como la transformación y degradación ambiental del corredor del río Consota se explica a partir del proceso de territorialización, cuya ocurrencia responde a factores estructurales políticos, socioeconómicos, culturales y naturales, originados en múltiples ámbitos (nacional, regional y departamental) y no solo en la escala local urbana, donde efectivamente el problema demuestra sus efectos. Así, la ocupación espacial de asentamientos humanos en este geocorredor $\mathrm{y}$, por tanto, los problemas ambientales que se suscitan en él, son una derivación y consecuencia en el nivel territorial local de fenómenos como el conflicto armado nacional, la cuestión agraria, la recesión y los bajos ingresos de la población, el desplazamiento y la migración de la población del campo a la ciudad, entre otros factores.

De esta forma, la naturaleza del problema objeto de investigación indica que las soluciones planteadas $\mathrm{y}$ las acciones por ejecutar no deben encaminarse solo a aquellas derivadas del diseño urbano y la ingeniería, sino también a las orientadas a resolver problemáticas nacionales pendientes, como es el caso de la tenencia de la tierra, la resolución de conflictos territoriales-armados, la ocupación laboral, entre otros.

\section{Referentes conceptuales: transformación $\mathbf{y}$ degradación ambiental desde una perspectiva geográfica}

En virtud del interés por encontrar y dilucidar nuevos caminos de entendimiento sobre la problemática ambiental resultante de la acción que los hombres ejercen sobre el entorno físicobiótico, en el proceso permanente de producción de la vida y de reproducción de la sociedad, es que se enuncian los conceptos que posibilitan explicitar los vínculos estrechos $\mathrm{y}$ multideterminados entre la sociedad (comunidad social y biológica) y el entorno en que circunscriben sus actividades. En este orden de ideas, se presentan las siguientes nociones propias de las ciencias sociales y, en particular, de la geografía.

\subsection{Espacio geográfico}

El espacio geográfico, como categoría de la realidad que expresa y denota la experiencia vivencial de las formaciones sociales, sus características, 
sus condicionantes, sus contradicciones, etc., circunscribe diferentes elementos, modalidades y componentes constitutivos, propios de su naturaleza histórico-social y natural. Sin embargo, su explicación y conceptualización presenta diversidad de enfoques y criterios, que históricamente se han ido validando, devaluando, sustituyendo o reutilizando; así, se ha pasado de nociones de espacio efectivo (abstracto), fijo, contenedor, absoluto ${ }^{4}$, a comprenderse el espacio en su generalidad, integrado por un componente biofísico que influye -pero a la vez es influenciado-, conformado y sobreconstruido por la esfera humana en sus diferentes estructuras y variables económicas, sociales, culturales, ideológicas, políticas, etc. De aquí que se entienda y asuma al hombre, y la sociedad en general, como sujeto (principal y determinante), y no como simple objeto (secundario y pasivo) en la concepción del espacio y sus procesos de configuración, constitución y transformación.

En efecto, el espacio geográfico se concibe como una categoría natural, social e histórica, que abarca diferentes interrelaciones. El espacio comprende los procesos y resultados de la acumulación histórica de las temporalidades del mundo biofísico (eras geológicas, ciclos del agua, del nitrógeno, periodos de meteorización, entre otros) con las temporalidades de la sociedad, que connotan los procesos de la producción, incorporación, integración y apropiación social de estructuras y relaciones espaciales en la biosfera terrestre" (Moncayo, 2001: 17).

Como considera Milton Santos (1996: 17), el espacio geográfico es un conjunto indisociable, solidario y también contradictorio de sistemas de objetos y sistemas de acciones. En relación con los objetos, este autor distingue entre objetos propiamente dichos y dones naturales. Los primeros son el producto de una elaboración social, mientras que los segundos resultan de la evolución del ecosistema natural. Pero la esencia y existencia de cada uno de ellos sucede siempre en relación con los otros. Además, hay que tener en cuenta que las cualidades y atributos de cada uno de los objetos y dones del espacio geográfico son, en determinado momento, fuente de interacciones, con las cuales se pueden encontrar las explicaciones a determinadas dinámicas espaciales.

En primer lugar, la idea de espacio fijo se asocia al espacio como escenario "inmutable y quieto" de la vida social, que sí es dinámica en su carácter histórico; en segundo lugar, el espacio como contenedor, en el cual están las cosas ocupando (o dejando vacío) el espacio mismo, y finalmente, como un espacio absoluto, que resume y ajusta las nociones anteriores, en el sentido de que considera que el espacio tiene existencia propia e independiente, es homogéneo y es el medio isotrópico en el que existen o se localizan los objetos, incluidos los cuerpos humanos y los objetos construidos. Citado con base en: Delgado M., Ovidio. Teorías sobre el espacio en la geografía contemporánea. Universidad Nacional de Colombia. Departamento de Geografía. Bogotá, 2000, pp. 7 y 8. 
Así mismo, la evolución histórica del espacio geográfico puede verse como el proceso de creación, acumulación y cambio de los objetos artificiales en la superficie terrestre y de transformación de sus dones naturales (Santos, 1996: 20). Este proceso demuestra la interconexión existente entre las formaciones sociales y el proceso de sobreconstrucción del espacio geográfico, en el cual ocurre simultáneamente, como efecto adscrito, la transformación y degradación ambiental. En este sentido, la comprensión de la problemática ambiental urbana transita por considerar las categorías (factores, elementos y relaciones) que intervienen en su ocurrencia.

Por esta razón, hay que abordar en primer lugar la condición de la naturaleza, tanto como categoría fundamental, como componente o factor constitutivo, pero no determinante, dependiendo del orden y ámbito en el que se examine. Este tipo de análisis es adelantado por Coraggio, al manifestar que "no todas las características de los estratos naturales pasan a ser categorías del ámbito social; pero evidentemente el ser humano y la sociedad, como un colectivo humano, comportan y se comprometen como una entidad de bases biológicas" (1983: 20). En otras palabras, las categorías del ser social están imbricadas con las categorías propias del orden natural, sin las cuales no puede existir efectivamente el todo social.

Para este autor, el espacio es determinación constitutiva de los objetos físicos, donde el término objeto no se limita a designar las cosas, sino también las relaciones, los procesos físicos. El espacio no es algo que esté "al lado de otros" objetos físicos, sino que es condición de existencia de estos ${ }^{5}$. De otra parte, mientras que el espacio no es una "propiedad" de los cuerpos, sí lo es la espacialidad (física), que expresa las cualidades de la extensión, la forma, la posición, la distancia, la dirección; por eso abarca también el movimiento y la conexión espacial (Coraggio, 1883: 22).

La comprensión de la espacialidad y la explicación de su lógica y esencia pueden descifrarse a partir de las leyes que regulan el fenómeno o proceso específico objeto de investigación (su organización y reproducción). En particular, la dilucidación de los fenómenos del orden natural se fundamenta en leyes físicas y biológicas; sin

5 Quedan así descartadas las concepciones que sustancializan el espacio y aun aquellas que lo presentan como un continente homogéneo, en el cual están todas las cosas ocupando (o dejando vacío) el espacio mismo. De ser así, las formas espaciales o las relaciones de posición o de movimiento podrían existir también "fuera del espacio" y eventualmente ser introducidas en él. Esta imposibilidad de existencia sin el sustrato espacial es lo que se señala al decir que el espacio es una determinación constitutiva (e inseparable) de las cosas y los procesos físicos mismos, o cuando se enuncia que estos son "espaciales". Tomado de: Coraggio, José Luis. Sobre la espacialidad social y el concepto de región. CEPAL. Santiago de Chile, 1983, p. 22. 
embargo, el impacto ambiental de la sociedad contemporánea ha generado que se incorporen nuevas ideas, con base en el hecho real de que el hombre puede cambiar e influir negativamente en la dinámica natural. Se demuestra así que el mundo físico no está totalmente regulado por las leyes del orden natural, de manera que hay que incorporar algunas leyes del orden social, con el propósito de interpretar y explicar la incidencia de la sociedad en el entorno, en su transformación. En definitiva, al sustentarse la relación sociedad-naturaleza desde este enfoque, se concibe que el mundo no está desgarrado en objetos de naturaleza diversa, unos puramente físicos, otros puramente orgánicos, otros puramente sociales, etc.; existe igualmente una posible articulación entre diversas espacialidades, en tanto una formación real compleja está entramada por determinismos de diverso orden de lo real (Coraggio, 1983: 23).

En una segunda instancia, se acomete el estudio de las estructuras del orden o ámbito social, entre las que se encuentran las variables o factores de la economía, la política y la cultura. En este orden se expresa cómo la economía determina e influencia en gran medida las configuraciones espaciales que inscriben las formaciones sociales. La acción económica del hombre en el espacio, y su relación con el medio, expresa cómo la naturaleza se transforma en objeto para el hombre, en instrumento de utilidad, en la medida que es enajenada del hombre a través del consumo. Las relaciones económicas se realizan (se hacen efectivas) como relaciones particulares, vinculando agentes concretos del sistema social. Tales agentes, en tanto tienen un sustrato físico, tienen una espacialidad fundada sobre momentos de la espacialidad física, como la posición relativa, la dirección del movimiento, etc., pero cuya lógica es social y no física.

En tercer lugar, se considera la politica como factor que interviene en la estructuración del espacio geográfico. A través de la comprensión de las conexiones que emergen entre los procesos políticos, el uso del poder y la utilización del espacio, se puede explicar a su vez la forma como se maneja y transforma el ambiente. De esta manera, el análisis de los problemas ambientales urbanos desde la perspectiva geográfica considera la incidencia de las relaciones tejidas por factores de índole político, en correspondencia directa con intereses económicos de grupos o agentes particulares en la construcción del espacio geográfico. Este señalamiento teórico enfatiza que las relaciones entre el ser humano y el ambiente pueden ser entendidas de manera adecuada por referencia al vínculo existente entre los patrones de uso de los recursos y las fuerzas económicas y políticas en la sociedad.

Además, el abordaje de los problemas geográfico ambientales requiere un examen del impacto que tienen el Estado y el mercado, como agentes de 
poder, en la forma como determinados grupos utilizan sus recursos naturales básicos, los transforman, alteran y simplifican, generando su degradación progresiva. Este tipo de análisis permite efectuar una exégesis del papel que juegan las relaciones de poder en los cambios presentes en las condiciones ambientales. Así, se reflexiona sobre cuáles son los agentes y actores que intervienen en los procesos de producción del espacio urbano y cuál es la correlación entre la participación de estos actores y el proceso progresivo de degradación ambiental urbana.

En cuarto lugar, se examina la variable cultural como factor que interviene en la construcción social del espacio $\mathrm{y}$, por consiguiente, en la transformación y degradación ambiental. En lo concerniente al estudio del medio y sus relaciones con el hombre, se parte del principio de no aceptación de un único sentido de lugar, puesto que empíricamente se puede demostrar que no todas las personas que residen en un mismo lugar experimentan los mismos sentimientos, ni con la misma intensidad, hacia el lugar que comparten.

Por el contrario, aparecen grupos de personas que presentan afinidades en lo que atañe a los lazos que establecen con el lugar en que residen. El lugar y su experiencia no es un proceso aislado, sino que se relaciona con otros procesos no siempre controlados ni tan siquiera percibidos, pero que influyen significativamente en nuestras vidas (trabajo, poder) y, por consiguiente, en nuestro sentido del lugar. Los sentidos de lugar aparecen, pues, como un juego de fuerzas cuyos componentes pueden ser, por una parte, la presencia de intereses o fuerzas estructurales que caen fuera del control individual y del grupo. "Estas fuerzas estructurales tienden a la cosificación de la vida, de la cotidianeidad y, por consiguiente, del espacio, que, como los demás objetos, son productos de las actividades humanas, y por tanto en las formas espaciales se representan los intereses de clase de acuerdo con el modo de producción dominante" (Estebanez, 1994: 53).

Además de esas fuerzas estructurales que tienden a crear un modelo territorial conforme con los intereses hegemónicos, existen en el hombre otras fuerzas más o menos desarrolladas, según el grado de alienación, que le incitan a reafirmarse, a buscar la identidad y el enraizamiento con el lugar. El juego de estos dos vectores produce una fuerza resultante que

\footnotetext{
El lugar es el espacio de relación más íntima entre los objetos naturales, la "naturaleza construida", las relaciones sociales y las significaciones culturales. La proximidad entre los agentes sociales, la semiología del entorno cercano y la convergencia de significaciones convierten el lugar en la célula espacial básica de las colectividades humanas, es una especie de totalidad territorial comunitaria mínima. Montañez. G. Gustavo. "Introducción: Razón y pasión del espacio y el territorio". En: Universidad Nacional de Colombia. Red de estudios de espacio y territorio, RET. Espacio y Territorios. Razón, pasión e imaginarios, p. 27.
} 
podemos denominar sentido del lugar. Por consiguiente, cada grupo o individuo está sometido a este doble juego de fuerzas contradictorias, cuyos efectos no son uniformes en todas las personas o grupos, de ahí la inexistencia de un único sentido del lugar positivo, negativo o indiferente (topofilia, topofobia o toponegligencia), sino que pueden darse personas y grupos que ante un mismo lugar experimenten reacciones adversas, es decir, nos encontramos con diferentes sentidos del lugar.

\subsection{Paisaje}

La disciplina geográfica ha planteado varios enfoques teóricos y metodológicos, a través de los cuales es posible explicar e interpretar los paisajes del presente. A su vez, hay múltiples aproximaciones desde diferentes disciplinas, pasando desde las características perceptibles que integran conjuntos espaciales determinados hasta abstracciones enlazadas con la imaginación y los pensamientos más puros (Molano, 1991: 11). El paisaje debe entenderse como decantaciones resultantes de la historia y sus estructuras socioeconómicas en el espacio geográfico. Es decir, la cultura objetivada (plasmada) en el espacio sobre bases inorgánicas y orgánicas de los escenarios naturales (Vidart, 1981: 15).
De igual manera, para cada momento, determinada forma de organización de la sociedad en el espacio geográfico que la contiene manifiesta una fisonomía, una manera de aparecer y un sentido de manifestarse (espacialidad); allí, en esa externalidad, aparecen los elementos físicos, bióticos, socioeconómicos y culturales. La conjugación de dichas entidades en un segmento concreto de las superficies terrestres integra el paisaje geográfico. Paisaje es, pues, apariencia, es integración fenoménica de procesos que se intuyen, es apariencia de esencias subyacentes. En sí mismo constituye un ordenamiento espacial que testimonia conjugación de tiempos plasmados en lugares donde se han sucedido, ya sean geoformas, manifestaciones bióticas, formas de organización social y conflictos ambientales, entre otros ${ }^{7}$.

El paisaje y los conflictos ambientales inscritos en él se aprehenden reconociendo las configuraciones espaciales que hoy vemos, que tenemos a nuestro alrededor, que heredamos, y mantienen una fisonomía propia como entidad espacial con los procesos socioespaciales que han precedido dichas configuraciones y que nos remiten a la espacialidad del tiempo en términos de paisajes pasados, plasmados por opciones económicas, políticas, culturales e ideológicas.

7 La configuración que recibe un territorio la producen tanto su geomorfología, ciertas condiciones climáticas, las redes de drenaje, etc., como también, y en gran medida, las acciones productivas y culturales, que tienen ciertos cambios que generan composiciones y recomposiciones de acuerdo con las opciones sociales que se suceden y con la dinámica que adquieren. Citado con base en: Molano B., Joaquín. Villa de Leyva. Ensayo de interpretación social de una catástrofe ecológica. Ed. Fondo FEN Colombia, 1994, p. 8. 
Los paisajes antiguos no se agotan al cambiar los procesos que los modifican, los ordenan y los producen, por el contrario, perduran con sus elementos, adquiriendo nuevo sentido y significaciones $^{8}$. En definitiva, la comprensión y esclarecimiento de los problemas ambientales exhibidos en el paisaje urbano devienen del estudio de la composición y estructuración de este ambiente "humanizado" a través del proceso histórico de ocupación y poblamiento del espacio geográfico.

\section{Metodología}

El análisis de los problemas ambientales urbanos se fundamenta en la interrelación de diferentes perspectivas de la geografía humana y física. De esta forma, se propone una metodología caracterizada por la interconexión y complementariedad entre los métodos cuantitativos y cualitativos. Los enfoques de la geografía humana intentan evidenciar los nexos entre los individuos y el medio, enunciados en los lugares y en la construcción social de estos, y tienen en cuenta las características culturales, políticas, económicas y naturales. A su vez, se presenta la estimación demográfica cuantitativa y el análisis de datos censales, el análisis fisiográfico (geografía física), entre otros.

Así, la investigación multimétodo permite una aproximación general y amplia que incluye los diversos factores biofísicos y sociales que actúan en la ocurrencia de los problemas ambientales. Para el desarrollo del análisis se efectúan, en primer término, las dos fases siguientes:

Fase 1. Preparatoria. En esta fase se definen los objetivos y la hipótesis; asimismo se analiza la percepción general que tienen de la problemática del área objeto de estudio los diferentes actores sociales involucrados.

Fase 2. Recolección de la información. En esta se identifica cuál es la información requerida, de acuerdo con los objetivos, la hipótesis y el modelo de análisis. La información de carácter social faltante es obtenida por una variedad de técnicas, como la observación participante, la entrevista, las historias de vida, etc. La información biofísica ausente se obtiene a través de técnicas como fotografías aéreas y comprobación en campo.

Posteriormente se adelantan las fases que integran el procesamiento y análisis de la información, la formulación del análisis geográfico territorial del área de estudio y los lineamientos generales de gestión ambiental territorial.

Fase 3. Procesamiento y análisis de la información. En esta se organiza e interpreta la información, con el fin de elaborar el análisis territorial desde la perspectiva geográfica, que permita describir y explicar la situación ambiental del tramo urbano del

8 Citado con base en lbídem, p. 9. 
geocorredor del río Consota con base en una mirada diacrónica.

Fase 4. Fase propositiva. Partiendo del análisis geográfico del corredor ambiental Consota en su tramo urbano y acogiendo las ideas de los diferentes actores en torno a la situación anterior, actual y futura de esta zona, se describen unos lineamientos básicos de gestión ambiental que posibilitan generar un nuevo aporte para la construcción de soluciones adecuadas a las complejas relaciones que se entretejen entre este espacio geográfico, la población asentada allí y los múltiples factores que desencadenan uno de los problemas ambientales más apremiantes del municipio.
En correspondencia con este enfoque metodológico, se presenta un modelo de análisis categorial-estructural, con el cual se intenta reconocer cómo se produce la degradación ambiental del tramo urbano del geocorredor del río Consota en el municipio de Pereira.

\subsection{Modelo de análisis}

Con el modelo de análisis ${ }^{9}$ soportado en las categorías de espacio geográfico, paisaje y territorio, se pretende explicar los problemas ambientales urbanos, no solamente desde la dinámica de los sistemas biofísicos, sino también desde su comprensión como producto de la actividad humana sobre el entorno, es decir, como un proceso ocurrido en el marco de la relación sociedad-naturaleza, ver figura 1.

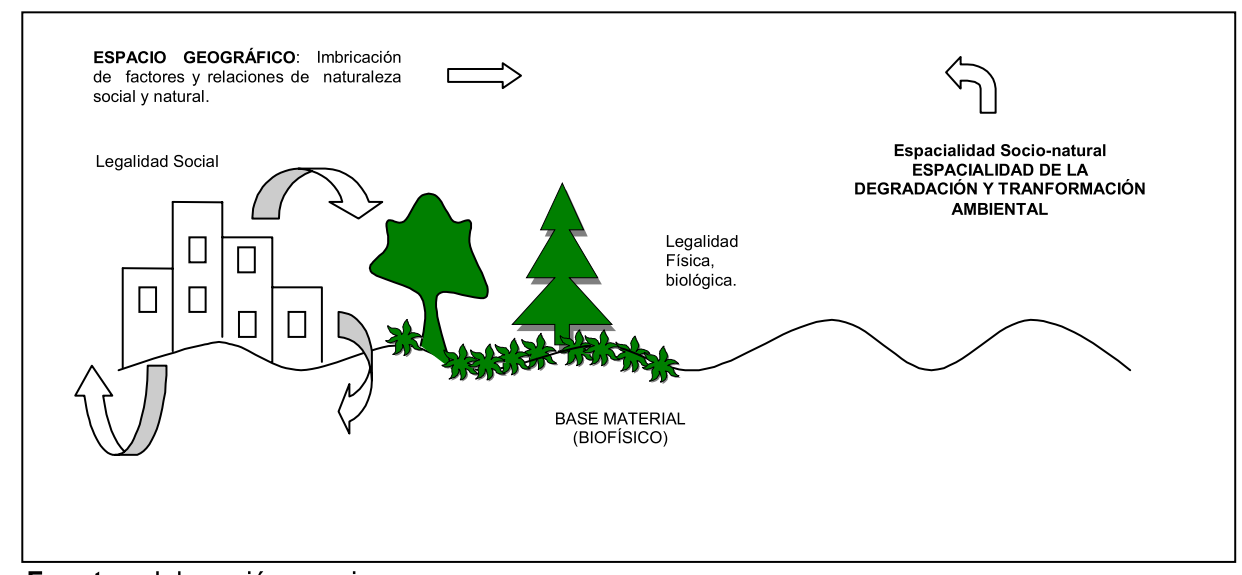

Fuente: elaboración propia.

Figura 1. Espacialidad de la relación sociedad-naturaleza.

9 El análisis categorial de un problema ambiental requiere: a) discriminar entre sus diversas modalidades de ser (natural y social); b) identificar las categorías propias de cada modalidad de ser (natural: físicos y bióticos; social: base natural, económica, política, cultural), y c) establecer cuál es la articulación entre las diversas categorías, así como el lugar que ocupan en la determinación del existente analizado. Citado con base en: Coraggio, op. cit., p. 18. 
De acuerdo con esto, se investiga de qué manera el hombre (comunidad social), a través del proceso de territorialización, incide en la dinámica del paisaje y en la conformación (transformación) del espacio geográfico. Con este propósito se intenta reconocer, en primer término, cómo los conflictos de carácter social, originados en diferentes ámbitos (nacional, regional, local), influyen en la ocurrencia del problema ambiental localurbano objeto de estudio, y en segundo término, cómo dicho problema encuentra su explicación a partir del reconocimiento de los múltiples factores que intervienen en su configuración, tanto desde la evidencia "más aparente" como fenómeno natural, hasta la dilucidación de las causas primigenias y "no tan aparentes" que lo ocasionan (la lucha por la propiedad de la tierra, el impacto social de la política económica, etc.).

Del mismo modo, el modelo de análisis considera el territorio con todas las especificaciones y rugosidades que se generan durante la realización de los procesos sociales, entendiendo que para que estos se produzcan se requiere de un soporte físico constitutivo del espacio, en el cual están presentes los elementos naturales (suelos, vida vegetal y animal, clima, geología, etc.). En este sentido, el modelo tiende a encontrar la explicación del fenómeno de degradación y transformación ambiental a partir de las leyes que lo regulan, que son tanto naturales como sociales.

En la figura 2 se muestra un esquema que representa la degradación y transformación ambiental en función de la categoría espacio geográfico, entendida como una estructura de la realidad donde existe una interdependencia de factores socionaturales, que se articulan como una entidad unitaria o única y no como la relación de dos entidades o estructuras independientes (por un lado un subsistema natural y por otro un subsistema social). Además, se tienen en cuenta las escalas que representan los ámbitos donde se ejercen las influencias y donde ocurre o se localiza el efecto ambiental estudiado.

ATEGORIA: ESPACIO GEOGRÁFICO

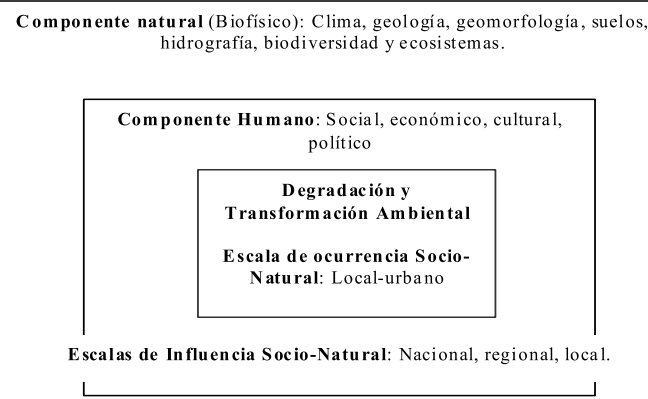


En la tabla 1 (anexo) se enuncian de manera general las variables y datos requeridos para adelantar el análisis de los problemas ambientales urbanos en función de los diferentes factores involucrados, y a partir de una mirada holística.

\section{Resultados}

\subsection{Referente espacial: Contextualización del área de estudio}

El área de estudio del geocorredor del río Consota se encuentra ubicada en la zona andina del territorio colombiano, entre la vertiente occidental de la cordillera Central y el valle del río Cauca; administrativamente, dicha área está localizada en el municipio de Pereira, departamento de Risaralda (ver figura 3).

La cuenca hidrográfica del río Consota drena un área de $157 \mathrm{~km}^{2}$, en un recorrido de aproximadamente $45 \mathrm{~km}$, des- de su nacimiento en la cuchilla el Corozal hasta su desembocadura en el río La vieja (Cartago). En este recorrido pasa por el área urbana de la ciudad de Pereira, en un trayecto cercano a los $9 \mathrm{~km}$, y es en esta área donde se ha generado, en la historia reciente del municipio, especialmente en los últimos veinte años, un proceso de transformación y degradación ambiental progresivo del geocorredor, debido a las características y tipología de la ocupación espacial de asentamientos humanos en dicho tramo de la cuenca.

El análisis del tramo urbano del geocorredor del río Consota se concentra, para este estudio en particular, en el sector comprendido entre el barrio Hamburgo hasta el barrio El Dorado. De esta forma, se delimita físicamente por la avenida Las Américas (vía arteria principal) al norte; por el Río Consota, al sur; al oriente, por los barrios Hamburgo, La Dulcera y La Platanera, y al occidente, por el barrio El Dorado (ver figura 3 $\mathrm{y}$ foto 1$)$. 
Figura 3. Contextualización del área de estudio.

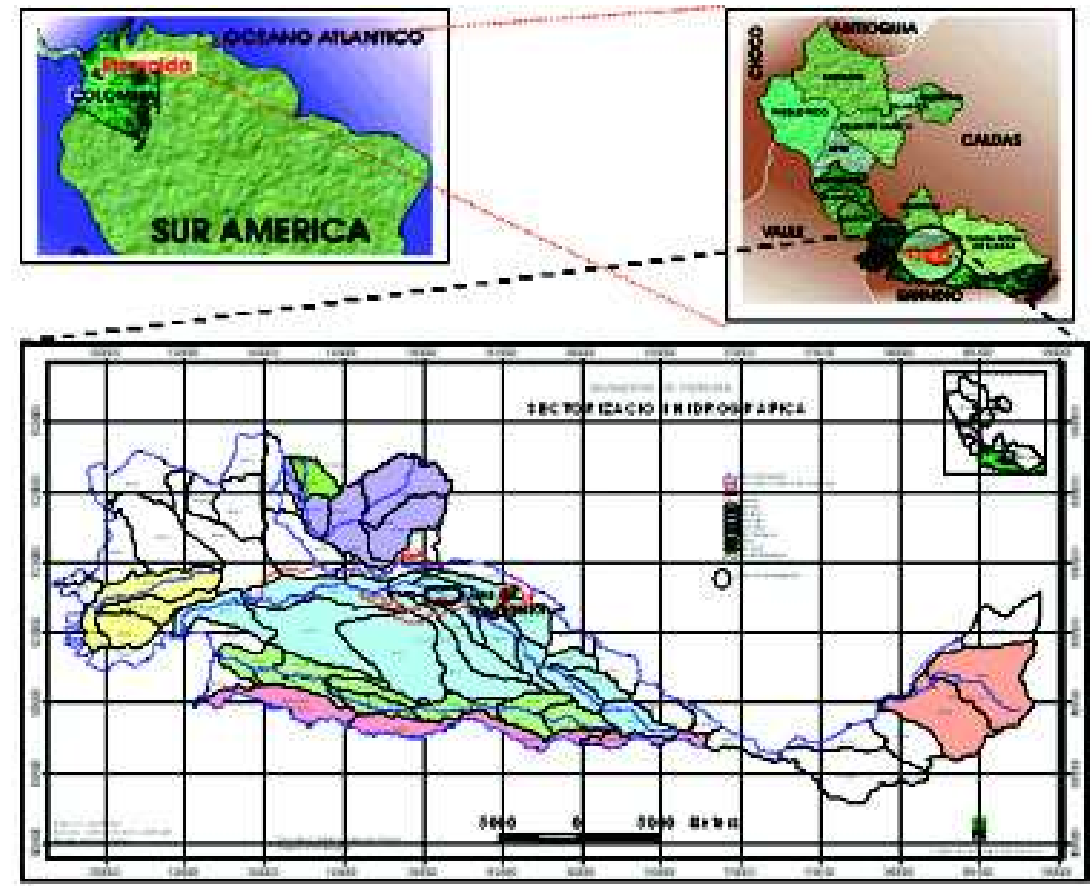

Fuente: CARDER. 2001.

Foto 1. Pereira. Localización del tramo urbano del geocorredor del río Consota: barrios La Dulcera, La Platanera, Hamburgo, El Poblado I y El Dorado.
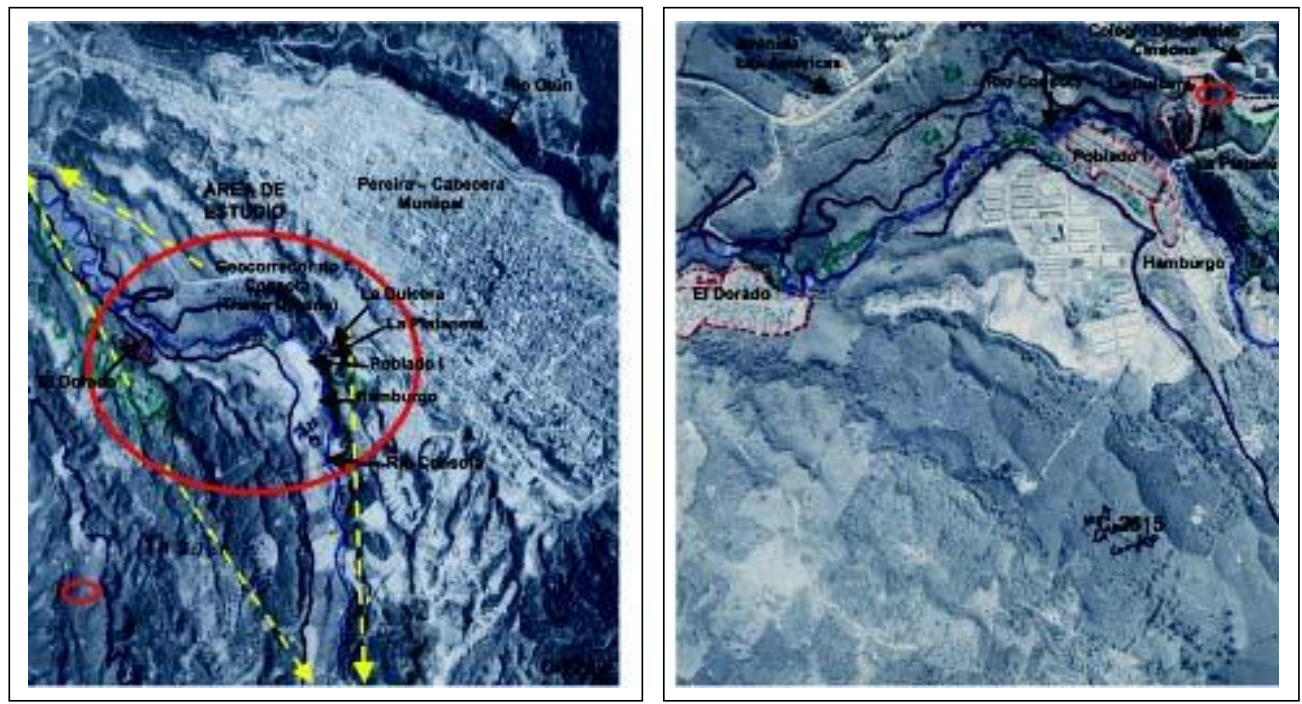

* En el año 1993 no se había conformado La Platanera; sin embargo se señala su ubicación actual. Fuente: IGAC. Fotografias aéreas C-2250, 1986; C-2515, 1993.4.2 Análisis geográfico del proceso de transformación y degradación ambiental.

266 Jorge Andrés Rivera Pabón 


\subsection{Análisis geográfico del proceso de transformación y degradación ambiental}

El proceso de territorialización acaecido en el geocorredor ${ }^{10}$ del río Consota en los últimos veinte años ha ocasionado su progresiva transformación y degradación ambiental; allí son evidentes fenómenos como la fragmentación de ecosistemas y cobertu- ras vegetales, al igual que procesos erosivos y contaminación hídrica (ver foto 2).

Como resultado del análisis geográfico de estos procesos dinámicos, se presenta la siguiente disertación, que sintetiza los problemas ambientales del geocorredor del río Consota en su recorrido por el tramo urbano del municipio de Pereira. Tabla 2 (anexo).

Foto 2. Pereira. Tramo urbano geocorredor del río Consota. Sector El Poblado-El Dorado. Procesos de fragmentación de ecosistemas y coberturas arbóreas.

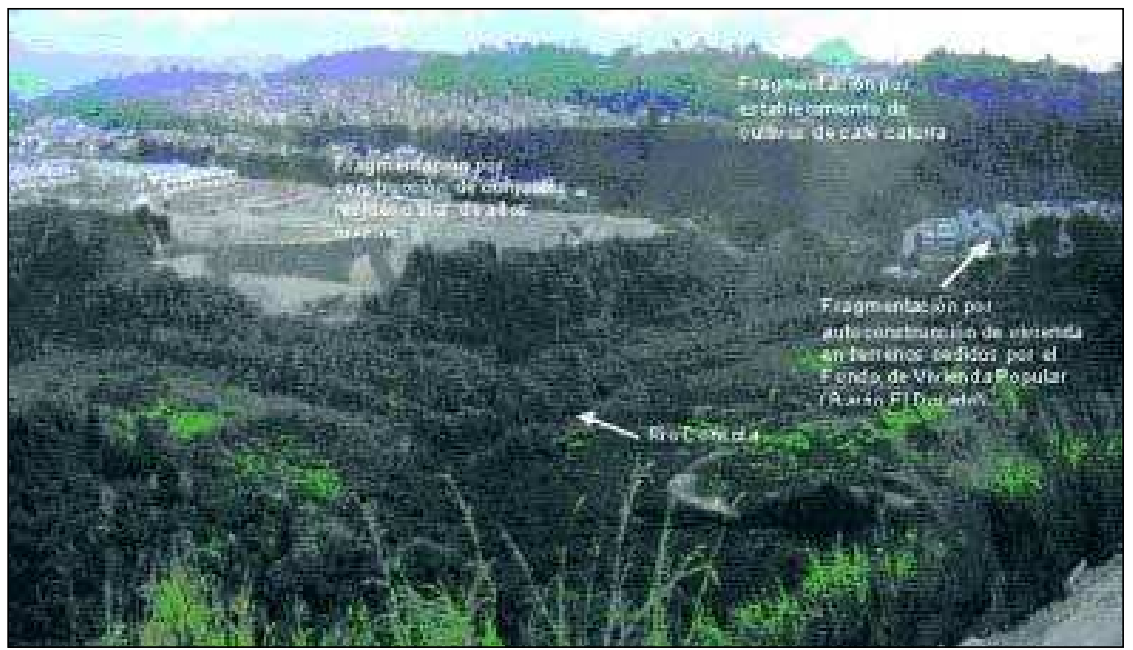

Fuente: El autor.

$\overline{10}$ El concepto de corredor ambiental se circunscribe tradicionalmente a teorías y estrategias de gestión provenientes de las ciencias naturales, en respuesta a problemáticas asociadas a la pérdida de la diversidad biológica y a las consecuencias que genera para la sociedad. Como estrategia de manejo permite a través de una franja lineal de vegetación proveer la continuidad entre dos hábitats; como expresión natural, se plantea como un recurso que se distribuye linealmente en el paisaje. (Bosques de galería o asociados a cursos de agua). No obstante, la misma configuración espacial del corredor como parches de ecosistemas unidos por franjas, es en algunas ocasiones la repercusión de la intervención ejecutada por comunidades sobre los sistemas naturales que les proporcionan bienes y servicios ambientales (tales como madera, fauna, etc.). Por esta razón, el interés por comprender la espacialidad de los corredores, al igual que los diversos factores que intervienen en su transformación ambiental (fragmentación), requiere incorporar nociones más interdisciplinarias. En consecuencia, desde el punto de vista geográfico, se expone el término "geocorredor", como proposición conceptual que manifiesta un espacio socionatural integrado en su constitución por diferentes temporalidades. 
4.2.1 Fragmentación de ecosistemas. El área de estudio expresa la simplificación y la fragmentación de ecosistemas y coberturas arbóreas, debidas a la intervención humana desarrollada a través de diferentes temporalidades. En primer lugar, se advierte cómo la percepción antropocéntrica del medio, de los pobladores europeos ${ }^{11}$, herederos de la tradición judeo-cristiana de una tierra diseñada para el hombre, generó la primera actividad extractiva de grandes proporciones durante la Conquista y la Colonia ${ }^{12}$. Es así como la visión ambiental de la cultura española privilegió el desmonte y la tala de las selvas, en razón a que este espacio geográfico era considerado "amorfo, inculto, montuoso, malsano e insalubre", percepción heredada, extendida y aplicada fervorosamente en la época de la colonización antioqueña ${ }^{13}$.

En segundo lugar, el ideal de progreso de la avanzada colonialista antioqueña se fundamentó en instaurar sobre la naturaleza "vacía" (de agentes y elementos "malsanos" ${ }^{14}$ ) un paisaje construido con base en las relaciones sociales y productivas de una agricultura extensiva y de la ganadería (extracción de selvas, praderización de vertientes y valles, etc.) ${ }^{15}$. De este modo, la materialización de este ideal se reflejó en la explotación extensiva agrícola de cultivos como el cacao y el café arábica, principalmente, durante los últimos años del siglo XIX y primera mitad del siglo $x x$. Sin embargo, este proceso de implementación del café, a pesar de que ocasionó la eliminación de selva natural primaria (de especies endémicas), se realizó dejando a su vez el café bajo la protección y relación ecosistémica, con coberturas de follaje denso, o por leguminosas del género Inga, como también de árboles frutales y diferentes cultivos de pancoger (plátano, yuca, fríjol, hortalizas, etc.).

11 Esta visión recaló y entronizó cultural e ideológicamente entre los hijos del mestizaje, siendo los patricios locales los principales voceros de dicha tradición sobre la representación de los "recursos" naturales, es decir, de una naturaleza por explotar.

12 Así mismo, otros indicios de grandes procesos de extracción de árboles en esta área se asocian con factores políticos de la época de la Conquista, ya que se elaboró una fortificación de madera que impidiera el paso a las tribus indígenas (Pijaos) que atacaban a Cartago Viejo, actual Pereira.

${ }^{13}$ Evidencia de esta construcción cultural es el monumento al hacha que existe en Armenia (Quindio), y que representa la idiosincrasia de la cultura del arriero.

14 Por esta razón, las principales fundaciones antioqueñas se ubican sobre los filos de las montañas y en lugares elevados, alejados de la manigua selvática, asociada a lugares proveedores de enfermedades, especies salvajes, etc.

15 Para abrir el debate sobre la tenencia de la tierra en el proceso de la colonización antioqueña, James Parsons expresa cómo "Jorge Villegas y otros han mostrado que eran algo románticas mis presunciones acerca de la sociedad democrática de pequeños propietarios o colonos y las virtudes sencillas de la vida campesina tradicional (maicera) de estas montañas. Parece, por ejemplo, que el acceso libre a la tierra para peones era bastante rara. El papel de los capitalistas y patrones y la especulación en tierras tuvo más énfasis del que recibió". Citado con base en: Las regiones tropicales americanas: Misión geográfica de James J. Parsons. Fondo FEN Colombia. Joaquín Molano B. (ed). 1992. p. 136. 
En contraposición, la explotación intensiva de tipo capitalista de cultivos como el café caturra, la caña de azúcar, los pinos, eucaliptos y el ganado en años posteriores requirió la extracción de grandes extensiones de tierra caracterizadas por las coberturas diversas y heterogéneas (en su composición y estructura arbórea), lo que condujo a la constitución de un paisaje en proceso de homogeneización.

Como resultado de este proceso de larga duración, se ha generado un mosaico de parches (remanentes, regenerados e introducidos ${ }^{16}$ ), matrices de pastos manejados, rastrojados y otros usos del suelo en el área de estudio (entre ellos la ciudad-construcciones), que denotan y explican la fragmentación de ecosistemas y coberturas arbóreas que exhibe actualmente el geocorredor del río Consota. Este hecho histórico (socio-natural) ha significado la pérdida progresiva de la conectividad estructural y funcional del geocorredor ${ }^{17}$, que sin lugar a dudas entraña las repercusiones ambientales de los desequilibrios territoriales, sociales y de la construcción cultural eurocéntrica que ha prevalecido en la utilización del medio habitado.

En particular, durante los últimos veinte años, factores de índole social (económico, cultural, político), manifestados en diferentes escalas (nacional, regional, departamental), como han sido el conflicto social y armado por la tenencia y propiedad de la tierra en el país, la agudización de la crisis del sector agrario a raíz de la aplicación nacional de las directrices del 'Consenso de Washington' sobre la apertura y liberalización económica y la disminución de funciones y responsabilidades socioeconómicas del Estado, entre otros, han ocasionado el desplazamiento forzado y el incremento de la migración campo-ciudad. Un gran receptor de esta población, en especial del centro-occidente del país y de la región del Chocó biogeográfico, ha sido Pereira.

De igual modo, la fragmentación acelerada durante este periodo encuentra su explicación en factores de índole social presentes en la escala local. La permanente explotación de las

16 Parches remanentes son fragmentos de coberturas arbóreas propias de selvas de primer y segundo crecimiento (en lenguaje de la biología, bosques primarios y secundarios), es decir, de aquellos espacios originarios y prístinos, sin ninguna alteración; y de aquellos resultado de procesos de regeneración natural después de un periodo de uso humano del entorno (Parches regenerados). Finalmente, los parches introducidos son aquellos creados por la actividad humana, como son los cultivos y actividades que resaltan en el "otrora" eje cafetero (ahora, más bien eje de los pinos de Cartón de Colombia, ganado, caña de azúcar para los "ingenios" de la región, etc.).

17 La conectividad estructural se refiere al grado de continuidad o integridad física del hábitat en el paisaje. Por otro lado, la conectividad funcional indica el grado en que las características de un paisaje y los elementos ecológicos que lo componen, facilitan o impiden procesos ecológicos como la diseminación de individuos. Citado con base en: www.catie.ac.cr. Notas de clase Profesor Bryan Finegan, Introducción a la ecología de paisajes. Ecología y Biología de la Conservación para el Manejo de Bosques Tropicales y Biodiversidad. 2003. 
coberturas arbóreas por la población que desarrolla la territorialización del geocorredor del río Consota se atribuye, en gran medida, a la necesidad de autoabastecimiento de los insumos y elementos básicos para la subsistencia, entre ellos están la madera para realizar sus construcciones, para la calefacción, como instrumento para la combustión que permita la cocción de sus alimentos, etc. En este sentido, para muchos de los habitantes del "lugar" el medio no reviste su principal preocupación, simplemente es imperativa la lucha por su supervivencia.

Por lo demás, es importante adentrarse en el análisis de los principales factores locales que motivan la constitución de estos asentamientos, sobre los cuales recaen "las culpas" de los impactos ambientales, como es el caso de la fragmentación. Dentro de dichos factores se encuentran actores con poder económico y político, que inciden en la conformación de asentamientos humanos y barrios, buscando su permanencia en el poder, es decir, en la toma de decisiones públicas, con el fin de hacer prevalecer sus intereses particulares (privados). Este fenómeno se hace evidente en la relación triangular entre los partidos políticos, las instituciones de la administración municipal que manejan las soluciones de vivienda y las organizaciones comunitarias de vivienda que buscaban legalizar las zonas invadidas.

Además, estos actores juegan un papel preponderante en la promoción de políticas y estrategias "públicas" de vivienda que favorecen la valoración y rentabilidad de las tierras en poder de las familias que monopolizan la propiedad del suelo urbano y las decisiones públicas locales. Así, se ha impulsado el proceso hegemónico de urbanización capitalista, que impide que la población desplazada e inmigrante de bajos ingresos pueda insertarse en el mercado legal de vivienda y le deja como única alternativa la progresiva ocupación espacial de las altas pendientes y de las vegas de los valles inundables, áreas de gran importancia ambiental en el ámbito urbano, por su gran biodiversidad.

En consecuencia, la fragmentación del geocorredor deviene de múltiples causalidades, elementos y factores, como los naturales, que explicitan la fragilidad ecosistémica de estos espacios de la zona ecuatorial, ante la acción humana; su perturbación suscita impactos sobre la naturaleza, en algunas ocasiones irreversibles, como es la disminución de especies de flora y fauna, debida a la pérdida de conectividad del corredor que permite la diseminación de individuos, etc. Así mismo, factores sociales que agencian y producen la espacialización de diferentes comunidades humanas en zonas no aptas para ser habitadas, por la vulnerabilidad que presentan a movimientos en masa o inundaciones, como consecuencia de la extracción y fragmentación de las coberturas vegetales. 
En este orden de ideas, la fragmentación del geocorredor del río Consota exhibe, desde el orden social que lo produce, dos características básicas en función de las escalas y los agentes que intervienen: en primer término, la relación con su contexto regional, en la medida en que la construcción social de este espacio geográfico es realizada por población desplazada de diferentes lugares del departamento y del país. Población que por factores socioeconómicos y políticos, como es el conflicto armado por la titularidad y propiedad territorial y el desempleo que sufre el campo colombiano, ha tenido que emigrar a Pereira para encontrar un lugar que le brinde la oportunidad de una convivencia pacífica y posibilidades de trabajo, realidad que difícilmente encuentra.

En segunda instancia se encuentran los factores del ámbito local, que demuestran cómo el fenómeno de fragmentación es causado por la configuración de asentamientos humanos y barrios en las laderas denudativas y las vegas de los valles. Pero no solo de aquellos originados por procesos de invasión, sino también de los que tienen su génesis en la planificación estatal de la "vivienda popular" y de los resultantes de la construcción de vivienda de altos precios. Esta argumentación desmiente la común y constante acusación sobre las comunidades de las áreas de invasión, de que son las únicas culpables de la pérdida de la biodiversidad y la belleza escénica de este lugar; muy por el contrario, la urbanización capitalista tiene gran responsabilidad en este proceso de deterioro ambiental de la ciudad.

\subsubsection{Procesos erosivos y fenómenos de remoción en masa. Los procesos} erosivos y los fenómenos de remoción en masa tienen lugar cuando las lluvias son abundantes y continuas, sin embargo, aparecen ligados, de una u otra forma, a la actividad humana. En general, los fenómenos activos de denudación observados dentro del área de estudio y su área de influencia próxima (zona cafetera), tales como deslizamientos superficiales, desprendimientos epidérmicos y arrastres lineares tipo barranco, ocurren en los taludes subverticales que limitan el valle del río Consota, en especial en el tramo urbano ${ }^{18}$.

De la misma forma como se examinó el problema ambiental de fragmentación de coberturas arbóreas y ecosistemas, los procesos erosivos encuentran su explicación en la imbricación de los procesos naturales y sociales. Desde el orden natural, se puede determinar cómo las condiciones climáticas que caracterizan la cuenca del río Consota, junto a las propiedades de los suelos ándicos que cubren

18 Los procesos geomorfológicos activos son escasos y localizados y están contrarrestados por una recolonización vegetal natural. Citado con base en: Villota, Hugo. Cartografía de la fisiografía y erosión de las cuencas de los ríos Otún y Consota-Barbas. CIAF. Bogotá, 1984, p. 52. 
la mayoría de sus unidades morfológicas, han sido determinantes de la poca presencia de rasgos continuos de erosión acelerada, especialmente de aquellos producidos por el escurrimiento difuso y concentrado, como sistemas de surcos y cárcavas.

No obstante, y desde el orden social, se puede fundamentar cómo en los últimos veinte años se viene presentando un mayor número de acciones humanas que generan procesos erosivos. En este sentido, en el ámbito regional y local se puede advertir cómo el cambio de una caficultura soportada en el café arábica -bajo sombrío y, por ende, acompañada de cultivos permanentes y transitorios- a una de café caturra -intensiva- ha llevado a la producción de una erosión laminar en las superficie colinada compleja, de cimas convexas moderadamente inclinadas.

Este proceso denota cómo factores de índole social (económicos y políticos) tienen relación con la dinámica de los procesos erosivos. Así, a raíz de la puesta en práctica de la política cafetera del Estado y de instituciones como la Federación Nacional de Cafeteros (comercio, manejo del espacio), se introduce con mayor vigor el café caturra en el geocorredor del Consota durante los años setenta y ochenta, lo que generó erosión difusa, debido a que el sistema de cultivo demandó todo el espacio para incrementar la productividad por área (sin sombrío), y para ello se empezó a talar y quemar la cobertura que existía ${ }^{19}$.

De otra parte, en el tramo urbano del geocorredor del río Consota, la ocupación espacial esporádica y permanente de asentamientos humanos sobre las laderas y taludes subverticales ha propiciado algunos movimientos en masa localizados. En la zona de estudio, los barrios La Dulcera y La Platanera, se han presentado fenómenos de remoción en masa tipo deslizamiento, escurrimiento difuso y erosión concentrada tipo surco. Los deslizamientos se han originado por la disposición de rellenos antrópicos y la posterior construcción sobre ellos, y su detonante ha sido la sobresaturación del depósito en eventos de lluvias fuertes (ladera empinada y características físicas del material de alta permeabilidad, falta de cohesión y confinamiento).

Así mismo, por la pendiente del terreno y la extracción de la vegetación en algunas áreas de la ladera, ocurren procesos de erosión superficial por escurrimiento difuso, debidos al golpe de las gotas de lluvia y al agua de escorrentía que se desplaza

19 Es importante anotar cómo este cambio en la caficultura se relaciona a su vez con la ampliación del latifundio como forma de tenencia de la tierra, debido a que los pequeños campesinos propietarios no podían mantener los altos costos de producción (fertilizantes, pesticidas, etc.) que requería la instauración del café caturra, viéndose obligados en muchas ocasiones a vender sus tierras, para que fueran incorporadas a este sistema de producción de características capitalistas. 
por la ladera y cauces de drenajes (secos generalmente). También, se han observado surcos causados por la entrega del alcantarillado a media ladera y por la ruptura del sistema de acueducto $^{20}$ en el barrio La Dulcera, o por la disposición de las aguas residuales domésticas (sin alcantarillado) sobre la ladera de pendientes empinadas a fuertemente empinadas.

De esta manera se demuestra la falta de acompañamiento permanente de los servicios requeridos (alcantarillado, líneas de conducción hasta los colectores pertinentes, que eviten la entrega de las aguas servidas domésticas a media ladera), la falta de capacitación continua a este sector de la población por parte de la administración municipal (Empresa de Aseo, jornadas educativas en procesos de reciclaje y disposición de residuos sólidos que prevengan la elaboración de rellenos con basuras) y, en especial, la falta de solución a los problemas de infraestructura y de prestación de servicios que pueden potenciar fenómenos asociados a los procesos erosivos, que los hacen vulnerables física y económicamente, aunque los estadísticas estatales digan lo contrario ${ }^{21}$.
De manera categórica se puede afirmar que en los procesos erosivos y movimientos en masa ocurridos en las laderas del geocorredor del río Consota (ver foto 3) subyacen las relaciones tejidas e intrincadas entre líderes políticos que han apoyado el establecimiento de asentamientos humanos $\mathrm{y}$, en general, la urbanización de áreas vulnerables a eventos catastróficos, y los estamentos públicos y privados de vivienda influidos por ellos (en los años ochenta y primeros de los noventa: Fondo de Vivienda Popular e Inurbe, y, posteriormente, instituciones de ahorro y vivienda y sector inmobiliario). De esta forma, la población desplazada e inmigrante de bajos ingresos ha vivido en constante "riesgo" de ser objeto de interés de actores políticos que desean preservar su hegemonía electoral a través de la "ayuda" a sus necesidades de vivienda, aunque el denominador común de estos barrios sea la ausencia de una infraestructura básica y su localización en zonas de posibles deslizamientos (La Platanera y La Dulcera) e inundaciones (El Dorado y Hamburgo).

20 CARDER. Actualización del inventario de viviendas localizadas en zonas de riesgo geotécnico e hidrológico en el municipio de Pereira. 2000. p. 45, 46.

${ }_{21}$ Según información de las Empresas Públicas de Pereira, en este sector existe un cubrimiento del $99,4 \%$ en la prestación del servicio de acueducto. En cuanto al tratamiento de aguas residuales, el cubrimiento es del $67 \%$; el $32,3 \%$ de las viviendas hacen vertimiento directo a la quebrada. En cuanto a recolección de basuras, se puede decir que el cubrimiento es de $100 \%$, ya que el carro pasa por todos los sectores, sin embargo, por problemas culturales la utilización es del $86,2 \%$; el $12,2 \%$ tiran las basuras directamente a las quebradas (lo que refuerza la idea de falta de capacitación). Citado por: Carder. Ibíd. 110. Las notas en paréntesis son mías. 


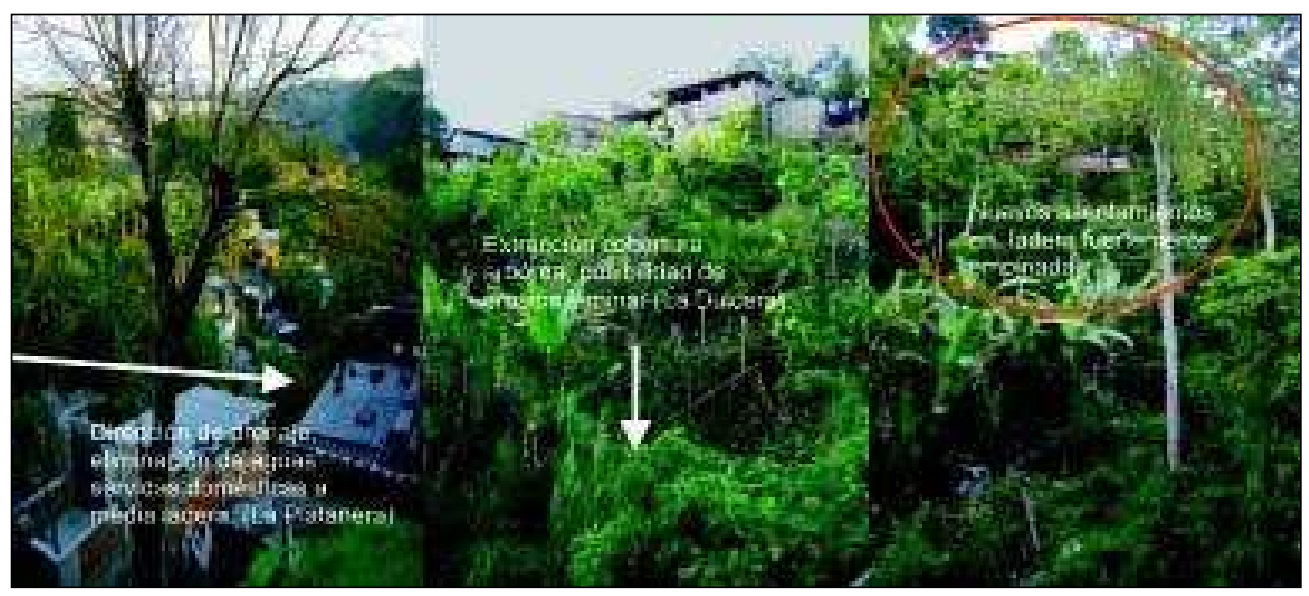

Fuente: El Autor.

\subsubsection{Contaminación hídrica. El} tramo urbano del geocorredor del río Consota evidencia un proceso progresivo de contaminación hídrica, resultado de las actividades productivas desarrolladas en el contexto municipal y local, de las características sociales de los asentamientos humanos localizados allí y del nivel de cubrimiento y eficiencia de la infraestructura de saneamiento ambiental y servicios públicos domiciliarios. De este modo, se puede afirmar que la actividad cafetera desarrollada a lo largo de la cuenca del río le ha proporcionado una carga alta de elementos contaminantes; las aguas mieles producidas contienen pesticidas, insecticidas y, en general, diferentes agroquímicos. Otro factor fundamental en la contaminación del río Consota es que en él desembocan algunos vertimientos líquidos provenientes del río Otún (industrial, doméstico y agrícola), ya que se realiza una transferencia por medio de algunos interceptores ${ }^{22}$ (ver tabla 3 ).

22 Es importante anotar que el río Otún recibe el 33\% de las aguas servidas y el río Consota, el $67 \%$ restante. Citado con base en: Porte. Documento Técnico de Soporte. 2000. 
Tabla 3. Aportantes contaminantes sobre la cuenca del río Consota

\begin{tabular}{|l|l|l|l|}
\hline $\begin{array}{l}\text { Sector } \\
\text { aportante }\end{array}$ & Descripción de componentes & $\begin{array}{l}\text { Carga } \\
\text { combinada } \\
\text { (Kg/d) }\end{array}$ & $\%$ \\
\hline 1. Población & Pereira (40\%). Aprox. 154.904 hab. & $16.033,0$ & 66,29 \\
\hline 2. Industria & Gaseosas Lux, Embotelladora Pereira (Coca Cola) & 523,4 & 2,16 \\
\hline 3. Agrícola & $\begin{array}{l}\text { Cultivos de café: Aprox. 602 hectáreas } \\
\text { Producción: Aprox. 14.800 ton/año }\end{array}$ & $7.630,0$ & 31,55 \\
\hline Total vertido & Cuenca del río Consota & $\mathbf{2 4 . 1 8 6 , 4}$ & $\mathbf{1 0 0}$ \\
\hline
\end{tabular}

Fuente: UCPR, 2003.

Los vertimientos líquidos en este subtramo urbano del río (barrios Hamburgo y El Dorado) son aguas residuales domésticas colectadas por el sistema de acueducto y alcantarillado; es importante mencionar que el sector se ve afectado, además, por la desembocadura de la quebrada Boston, que aporta aguas residuales de las comunidades ubicadas en su zona de influencia (ver tabla 4).
Para identificar la calidad del agua en este subtramo del río Consota, se toma como punto de muestreo la desembocadura de la quebrada Boston, de tal forma que los valores no evidencian solamente el comportamiento del río Consota como receptor directo de aguas residuales domésticas de los habitantes del subtramo (aproximadamente $1.159 \mathrm{~m}^{3}$ por día), sino también la importancia de los afluentes, que a la vez son receptores y aportantes de vertimientos (UCPR, 2003: 151).

Tabla 4. Variación de parámetros de calidad del agua río Consota

\begin{tabular}{|l|c|c|c|c|c|}
\hline $\begin{array}{l}\text { Fecha de } \\
\text { monitoreo }\end{array}$ & DBO $_{\mathbf{5}}(\mathbf{m g} / \mathbf{l})$ & OD (mg/l) & $\begin{array}{l}\text { Coliformes } \\
\text { fecales }\end{array}$ & IFSN & Calidad del agua \\
\hline Ago-93 & 6,5 & 6,57 & $4,4 \times 10^{5}$ & 64,04 & Regular \\
\hline Jun-97 & 4 & 6,97 & $2,4 \times 10^{4}$ & 58,67 & Regular \\
\hline Ago-01 & 3,7 & 4,85 & $7 \times 10^{8}$ & 63,62 & Regular \\
\hline
\end{tabular}

Fuente: Estudio de factibilidad de tratamiento de aguas residuales de Pereira. Informe final. Componente 1. Aguas y Aguas de Pereira. 2002. 
De acuerdo con las mediciones realizadas en el punto de muestreo mencionado para el subtramo, el oxígeno disuelto en el agua ha disminuido hasta presentar valores inferiores a los 5 miligramos por litro, lo cual compromete su capacidad de autodepuración y restringe la presencia de vida acuática. Igualmente, el comportamiento de la demanda bioquímica de oxígeno y la presencia de coliformes fecales manifiestan valores altos, que expresan el deterioro de la calidad del agua. Esto se relaciona directamente con la disminución en el cubrimiento del alcantarillado, en razón del incremento en la demanda, pues algunos asentamientos humanos de población desplazada se encuentran en continuo aumento y no son atendidos por el servicio de alcantarillado. Tal es el caso del asentamiento de La Platanera y de otros que se desarrollan dispersos en las laderas y las vegas del río y que no son tenidos en cuenta por las estadísticas de la administración municipal y de otras instituciones que, por el contrario, exhiben datos de un cubrimiento eficiente de todos los servicios públi$\cos ^{23}$. Según las encuestas realizadas en La Platanera, aproximadamente el $10 \%$ de las personas entrevistadas ex- presaron que sus viviendas contaban con servicio de alcantarillado, y estudios realizados en la zona señalan que "las viviendas localizadas en el sector de la calle de dirección norte-sur no poseen conducción (que son la mayoría), por lo tanto, las aguas residuales son entregadas libremente a la ladera, condición que en un futuro cercano puede generar procesos de inestabilidad en ella. El alcantarillado de las viviendas localizadas en dirección oriente-occidente es captado por una tubería, que entrega a una recámara localizada en la depresión occidental" ${ }^{24}$.

Los datos anteriormente enunciados reiteran la incidencia que ha tenido la constitución de asentamientos humanos -caracterizados por su precariedad en la prestación de servicios públicos domiciliarios- en la generación de los conflictos ambientales del tramo urbano del geocorredor del río Consota, entre ellos la contaminación de sus aguas. Sin embargo, las razones que motivan esta problemática van más allá de los "aparentes causantes" del deterioro ambiental (población desplazada, denominada en los ejercicios de planificación y académicos: población en subnormalidad, cinturo-

23 En lo referente a servicios públicos de energía, acueducto, alcantarillado y aseo, el tramo comprendido entre el parque El Vergel y el barrio El Dorado presenta una cobertura del $92 \%$, de acuerdo con las estadísticas que a continuación se enuncian. En cuanto al tipo de alumbrado utilizado, tenemos que el $99,8 \%$ es eléctrico. Con relación al sistema de eliminación de excretas, el $82,2 \%$ posee inodoro conectado a alcantarilla, el $11 \%$ no tiene estos servicios y el $4 \%$ tiene inodoros sin conexión al alcantarillado. En referencia al sistema de abastecimiento de agua tenemos que el $99,2 \%$ es a través del acueducto. Para las disposiciones de las basuras, el $91 \%$ son recogidas por el servicio de aseo y el 7,6\% la tiran al lote o al río. UCPR, Ibídem, p. 248.

24 CARDER. Actualización del Inventario de viviendas localizadas en zonas de riesgo geotécnico e hidrológico, en el municipio de Pereira. Capítulo 7. Barrio La Platanera. 2000, p. 58. 
nes de miseria, etc.) y se ubican en los factores y procesos sociales (políticos, económicos y culturales), que son los precursores y génesis de su desplazamiento (procesos migratorio campociudad) y de su localización en las zonas que habitan en las áreas urbanas.

En este sentido se insiste en que, dejando de lado "el espectro del mundo aparente", se descubren los verdaderos procesos, elementos y actores que promueven y son la base de la transformación y degradación ambiental del geocorredor. Así, la relación explicitada anteriormente, entre partidos políticos, actuaciones administrativas públicas, mercado inmobiliario $\mathrm{y}$ organizaciones de vivienda en la escala local, por una parte, y tenencia de la tierra, conflicto armado, crisis agraria (cafetera) y desplazamiento -en el contexto regional y nacional-, por la otra, ha ocasionado la territorialización de tantos barrios en áreas de difícil habitabilidad y cobertura de servicios. Barrios proclives a verse afectados por fenómenos naturales (crecidas de río, terremotos, etc.), a generar fragmentación de coberturas arbóreas y ecosistemas, como también a producir la contaminación de los drenajes y ríos, por la baja cobertura en el servicio de alcantarillado, que tiene como efecto un inadecuado sistema de evacuación de las aguas residuales (ver foto 4 ).

\subsubsection{Gestión ambiental: linea-} mientos generales. Como resultado del análisis geográfico de la transformación y degradación ambiental del geocorredor del río Consota, se exponen unos lineamientos generales de gestión ambiental que responden a la naturaleza del problema objeto de estudio, es decir, la presencia de conflictos ambientales derivados de la interrelación de diferentes factores y variables en un todo socionatural.

Foto 4. Contaminación hídrica del río Consota tramo urbano Pereira.

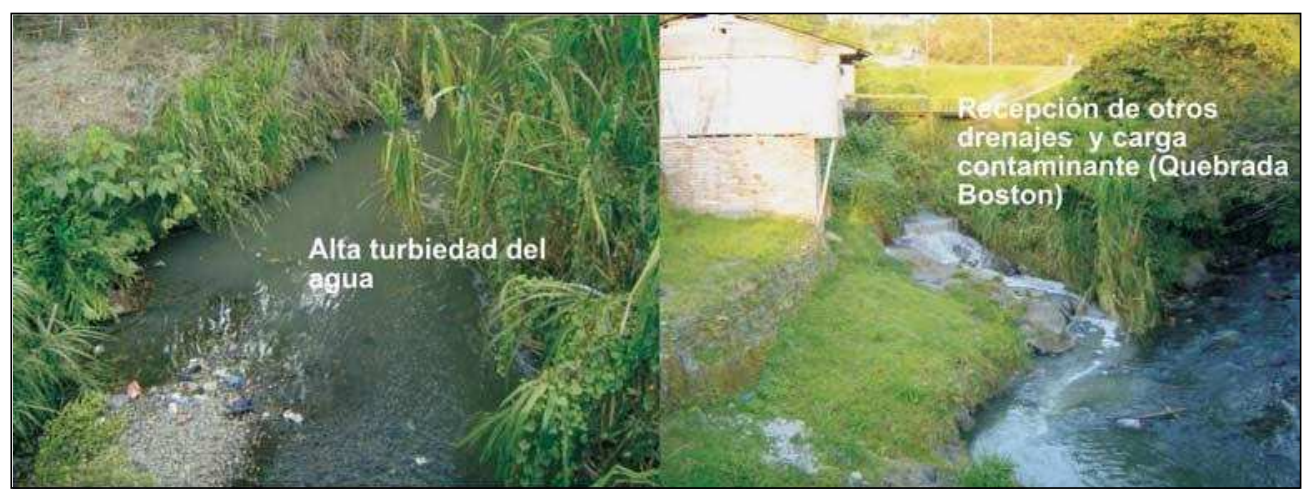

Fuente: El autor. 
De esta forma, como ya se dijo, los instrumentos de gestión y las acciones por ejecutar no deben encaminarse solo a aquellos derivados del diseño urbano, los proyectos tecnológicos $\mathrm{y}$ la ingeniería civil, ambiental y sanitaria $^{25}$, sino también a los orientados a resolver problemáticas sociales pendientes, del ámbito nacional, regional y local, que demuestran sus efectos en el corredor ambiental del río Consota, espacio geográfico que se encuentra en proceso progresivo de territorialización y urbanización. En este sentido, se deben modificar las amplias fuerzas condicionantes de naturaleza política, económica y cultural que actúan en el espacio y las relaciones entre los grupos humanos y su entorno.

En este orden de ideas, los problemas sociales que generan o inciden en los conflictos ambientales urbanos que se suscitan en el geocorredor deben ser enfrentados mediante las respectivas políticas estatales, de aplicación en el contexto regional, departamental y local, que han sido aplazadas permanentemente. Así, se hace urgente y perentorio dar inicio a los siguientes procesos:

\section{- Resolución del conflicto territorial} armado, con el propósito de minimizar el desplazamiento forzado y la inmigración a las ciudades (caso Pereira, geocorredor del Consota), que se realiza con el fin de salvaguardar la vida y la integridad familiar. Este proceso no se llevará a cabo hasta tanto no se enfrente el siguiente punto $^{26}$.

- Cuestión agraria. En el país es necesario adelantar un proceso de reforma agraria que permita la redistribución equitativa de la tenencia de la tierra, para que muchas personas permanezcan en el campo y otras vuelvan a él. Para ello hay que tener en cuenta los antecedentes o procesos desarrollados, es decir, generar una reflexión sobre los aspectos que impidieron su realización y las posibilidades futuras de su consecución, al tenor de la realidad actual del país y el mundo.

En cuanto a los antecedentes, es importante destacar la Ley 135 de 1961, en la cual se enunciaron diferentes elementos

$\overline{25}$ La problemática ambiental de esta zona de Pereira, de manera insistente, se enfrenta con planes, programas y proyectos de gestión que son necesarios, pero en su aplicación y resultados finales son limitados, "reduccionistas" y muchas veces no llevados a la práctica (por los altos costos), ya que centran su atención y se enfocan en el mejoramiento estético, la construcción de obras de ingeniería como muros de contención, gaviones, sistemas de colectores y saneamiento, etc.

26 De acuerdo con la política estatal del presidente Álvaro Uribe Vélez, el conflicto armado del país se resuelve a través de la "seguridad democrática -todos en pie de lucha contra los terroristas-" y el enfrentamiento y confrontación abierta contra los grupos subversivos (conformados mayoritariamente por campesinos desplazados de sus tierras), y no mediante una reforma agraria y distribución equitativa de la tierra entre los campesinos para que puedan desarrollar sus vidas y proyectos productivos, sin necesidad de irse a la guerra como único camino de subsistencia. 
y criterios para la reestructuración de la tenencia de la tierra, el fomento de la producción y la productividad, elevación del bienestar de la población campesina, conservación de los recursos naturales y promoción de la organización campesina ${ }^{27}$. Entre los criterios y principios de la ley se citan:

a. El orden para la adquisición de las tierras es: mal explotadas, inadecuadamente explotadas $y$, en casos especiales, las tierras bien explotadas (art. 55).

b. El grado de explotación se determina por factores físicos, económicos $\mathrm{y}$ geográficos, sin mayor precisión (art. 56). Es el llamado criterio subjetivo, que permitió operar al Incora, aunque muy lentamente, y es lo que trataron de desmontar los mínimos de productividad de la Ley 4 de 1973.

c. Se contempla la expropiación de predios bien explotados cuando sea necesario ampliar zonas de minifundio o ensanchar parcelas de arrendatarios o aparceros.

d. Las formas de pago se harán según el grado de explotación de las tierras. Las tierras inadecuadamente explotadas y de arrendatarios y aparceros se pagan con bonos a 20 años e intereses del 2 al $4 \%$ anual.

- Tenencia de la tierra urbana, planeación del desarrollo urbano y ambiental participativo. A la par de una reforma agraria se debe realizar una reforma urbana que permita minimizar el monopolio del suelo urbano, ejercido por "gamonales" que hacen parte de familias con poder económico y político $\mathrm{y}$, por tanto, con influencia en el direccionamiento de las políticas públicas del manejo de la tierra y la vivienda y con injerencia en el mercado inmobiliario y la urbanización de tipo capitalista en la ciudad. De esta forma, se deben determinar políticas de desarrollo urbano y planificación ambiental participativa $\mathrm{y}$ vinculante con todas las comunidades, que privilegien los interés generales de la sociedad sobre los beneficios particulares y privados de los terratenientes urbanos; es así como el sector público deberá definir e implementar estrategias de administración del territorio y la construcción de ciudad, para minimizar los impactos ambientales urbanos inscritos en el marco de la relación sociedad-naturaleza. Para ello se propone:

a. Consolidar una política estatal de vivienda de interés social y de bancos

2 Para una reseña de los puntos de vista, logros de la reforma agraria, etapas de la reforma (acción lenta: 1962-1966; considerable acción reformista: 1967-1972: desmonte de la reforma agraria: 19731983; recientes proyectos: 1984-1987; el DRI, etc.) véase Machado, Absalón: "Una mirada retrospectiva". En: Transformaciones en la estructura agraria. Minagricultura 80 años. Tercer Mundo Editores. Bogotá. 1994, pp. 97-146. 
de tierra pública municipal, que permita responder a la demanda de vivienda de la población actual y proyectada del municipio ${ }^{28}$, evitando la ocupación espacial de asentamientos humanos en zonas de riesgo y en áreas de interés ambiental (corredores ambientales de los ríos y quebradas). Este proceso se logrará en la medida que se busque una gestión mixta (público-privado), pero a favor de todos los segmentos de la población.

b. Promover la educación ambiental como estrategia para mantener y preservar la naturaleza, para consolidar el respeto, la valoración y la identidad con los recursos naturales, y en particular con los cuerpos de agua, enfatizando en el reconocimiento de la función natural y social que cumplen (abastecimiento de agua para la población, uso recreativo, articulación de los elementos que constituyen el espacio público). Esta estrategia incluye la vinculación laboral de la población del geocorredor como intérpretes ambientales, pues son ellos precisamente los que conocen y se identifican con el lugar. De igual manera, se deben realizar procesos de capacitación por parte de la autoridad ambiental (CARDER) y diferentes universidades de la ciudad y región (UTP, UCPR, Libre, etc.) para estas personas. Es importante anotar que la estrategia se fundamenta en la información suministrada por los pobladores de la zona, ya que a través de las historias de vida y de la observación participante se pudo constatar que "existe una relación cotidiana y de sentido con el río Consota, en la medida que este servía como espacio de aseo, preparación de alimentos, recreación activa y pasiva, lavado y secado de ropa, etc.".

c. Fortalecer la participación ciudadana, incentivando el trabajo comunitario (educación ambiental, ecoturismo urbano, etc.), la organización social y el compromiso colectivo para adelantar la recuperación y conservación del río Consota y sus afluentes.

d. Asegurar la prestación de los servicios públicos domiciliarios y de saneamiento ambiental básico para el municipio, disminuyendo de esta forma la contaminación hídrica y los factores causantes de los procesos erosivos (por falta de alcantarillado, se disponen los vertimientos líquidos a la ladera).

e. Aplicar los programas de gestión integral de residuos sólidos. En último lugar, la disposición inadecuada de los residuos sólidos en las márgenes del río, sus afluentes y la ladera, se presenta debido a la falta de aplicación de un programa integral de gestión de los residuos sólidos. A pesar de que

\footnotetext{
${ }^{28}$ La población referida es aquella que se encuentra en condiciones de vulnerabilidad económica y ambiental, por indicadores como la línea de pobreza y ubicación en zonas de riesgo. Esta población debe insertarse en procesos de reubicación, priorizando las viviendas en zonas de riesgo alto no mitigable.
} 
las estadísticas de la administración municipal indican que todo el tramo está cubierto por el servicio de recolección de basuras ${ }^{29}$-incluso en el barrio El Dorado existen asociaciones comunitarias dedicadas al reciclaje de residuos-, lo que se pone de manifiesto es la falta de interés de la administración municipal y las instituciones encargadas del manejo ambiental y sanitario en acompañar más activamente a este sector de la población pereirana. La falta de capacitación en la comprensión de la problemática ambiental y el poco apoyo en recursos y asistencia para seguir avanzando y hacer crecer los procesos de reciclaje, desestimulan y limitan su operación.

La integración de estas acciones o estrategias ambientales (de carácter social, técnico y natural) permitirá la minimización de las acciones de transformación del paisaje ocurridas en el proceso de poblamiento y crecimiento urbano del municipio.

\section{Conclusiones}

El proceso de transformación y degradación ambiental del geocorredor del río Consota proviene de la territorialización histórica de este espacio geográfico. La ocupación y el poblamiento, llevados a cabo desde la época prehispánica hasta la época contemporánea, manifiestan cómo los cambios acaecidos y evidenciados físicamente guardan una fuerte relación con la organización social, su estructura económica y los fenómenos y eventos resultantes de las luchas y confrontaciones por el poder y dominio del espacio. De esta forma se puede concluir que este espacio natural es sobreconstruido por la actividad humana (es un "espacio socialmente construido"), actividad que es determinada por múltiples factores culturales, económicos y políticos que responden a un momento histórico social particular.

Este paisaje de "geocorredor" es resultado de un proceso histórico de humanización, “objetos culturales" sobre una base natural. Así, es preciso anotar que el paisaje actual del municipio es efecto de las mutaciones que ha experimentado desde lo funcional hasta lo estructural en diferentes periodos históricos.

2 Según la administración municipal, en los barrios Hamburgo y El Poblado I existe un sistema de recolección de residuos acorde con las necesidades de la comunidad, por lo cual no se evidencia una situación crítica frente a los desechos sólidos, sin embargo, algunos habitantes arrojan los residuos domésticos a las márgenes del río. Citado con base en: UCPR, op. cit., p. 248.

En este sentido se evidencia cómo al cumplir con la recolección se cree cumplida la gestión, y no se realiza ninguna tarea adicional para mitigar y acabar con la arrojada de residuos al río por los "pocos pobladores" que aún lo hacen. Esta población, así sea reducida, requiere de un proceso de capacitación y educación ambiental, para que no continúen con esta actividad, y se logre evitar la contaminación hídrica por residuos sólidos, por lo menos en este trayecto. 
El cambio en el uso (funcional) de este territorio, de actividades propias de comunidades indígenas (cultivos tradicionales, etc.) a explotación característica de zonas mediterráneas (pastoreo, ganadería, agricultura con especies introducidas), condujo a un primer momento de degradación por reducción (tala, quema, etc.) de las especies originarias o endémicas del lugar. Posteriormente se consolida la economía campesina (agropecuaria), como motor productivo, diferenciándose a través de los años por las relaciones sociales de producción y los medios e insumos utilizados.

De esta forma, se reflejan diversos procesos de degradación ambiental, asociados a tipologías de economía rural. Una de estas son las pequeñas unidades (minifundios), que han utilizado cultivos transitorios y permanentes (algunos de ellos altamente impactantes, como cultivos limpios) en las laderas y piedemontes; sin embargo, esto se ha producido por la presión ejercida por las condiciones económicas y sociales (cambios estructurales, como la cuestión agraria: tenencia de la tierra, políticas agrícolas, etc.), que tienen gran impacto sobre el ambiente. De otro lado, se han presentado actividades de explotación silvoagropastoriles, de mayores recursos financieros y económicos, que han utilizado mecanismos e insumos para elevar su productividad (uso de agroquímicos auspiciados desde los años sesenta por la revolución verde, instaurados en la caficultura caturra, la producción de caña de azúcar, forestales de pinos y eucaliptos, etc.), los cuales han coadyuvado para alcanzar el nivel de transformación y deterioro del paisaje resultante actualmente.

Durante los últimos veinte años, los mayores determinantes de la transformación y degradación ambiental del corredor del río Consota han sido, por un lado, la crisis del sector rural (pauperización del sector agrario-cafetero, que ha ocasionado procesos migratorios acelerados, el conflicto territorial y armado), y por otro, el tipo de urbanización capitalista que domina la construcción de la ciudad y que no ha permitido la inserción de las poblaciones migrantes a la vivienda de "tipo legal", produciéndose como consecuencia el establecimiento de viviendas y barrios de invasión en zonas con limitaciones para ser habitadas, dados los condicionantes biofísicos, entre ellos, las llanuras aluviales de inundación y las laderas con procesos denudativos.

De este modo, la expansión acelerada de la ciudad sobre áreas periféricas y periurbanas y la inserción de espacios naturales (de características rurales) al crecimiento urbano se han promovido en el momento de la hegemonía del gran capital promotor, que en realidad es el que ha definido, en gran medida, los ritmos y las direcciones de la urbanización; es claro que donde los controles públicos sobre la producción del espacio urbano no están suficientemente desarrollados, el gran capital 
promotor tiene las más amplias posibilidades de operación.

Precisamente, se puede explicar el desarrollo urbano de estas zonas señalando la relación entre los terratenientes urbanos -que han adquirido las tierras baratas, anticipando la urbanización-, la posterior llegada de los promotores y constructores, y, en último lugar, la actuación de los gobiernos locales y de los órganos de planeamiento, favorable a los intereses inmobiliarios. Es así como a partir de los compromisos, acuerdos y las distintas alianzas establecidas entre los grupos políticos, agentes y actores sociales en torno de las intervenciones en la transformación de los espacios periféricos, se ha formalizado la "red de crecimiento" de la ciudad.

Efectivamente, el proceso de territorialización adelantado durante la década de los ochenta en el geocorredor del Consota testifica que los asentamientos humanos de La Dulcera y El Poblado I han correspondido a dos tipologías diferentes en su origen y constitución, pero ambas subyacentes a las relaciones entre actores económicos y políticos. El primero, asociado a un proceso de invasión, y el segundo, resultado de los ejercicios de planificación estatal de la "vivienda popular". De manera particular, la expresión de territorialidad, que tuvo su origen en un proceso de invasión (La Dulcera), certifica cómo fue permeada por los grupos de poder, generándose una relación triangular entre las organizaciones de vivienda, la administración pública y los partidos políticos, y el deseo de estos de permanencia en el poder.

Igualmente, se puede afirmar de manera concluyente que la transformación y degradación ambiental del geocorredor (fragmentación de la cobertura arbórea existente, etc.) es determinada, en gran proporción, por el proceso de urbanización y territorialización reciente de asenta-mientos humanos, sin extender culpabilidad o señalar de facto a la población que conforma dichos asenta-mientos; muy por el contrario, en la perspectiva de reconocer las verdaderas causalidades, se limita la responsabilidad de los desplazados y población en línea de pobreza, que luchan diariamente por su supervivencia, y para quienes, en medio de sus difíciles circunstancias, los recursos naturales y los servicios que prestan no son, desde una perspectiva ecológica, el centro de su preocupación.

En este sentido, las consecuencias ambientales de la territorialización del geocorredor se dilucidan a partir de los factores expuestos con anterioridad, como la relación entre los grupos de poder económico y político, que trazan las directrices del uso del suelo y manejan el mercado de la construcción de vivienda, y la invisibilidad de una política pública de vivienda.

De otra parte, es pertinente sugerir que para entender las relaciones y ámbitos que recrean y producen los problemas 
ambientales urbanos es necesario incorporar a los estudios ambientales la perspectiva social, histórica y multiescalar, ya que, en general, no se tiene en cuenta la naturaleza de las contradicciones que subyacen al fenómeno de la urbanización capitalista, las características sociales, culturales, demográficas y políticas de la población que realiza los procesos de territorialización, la geohistoria de la construcción social del espacio geográfico y tampoco las diferentes escalas en que se desarrolla la génesis de los problemas sociales, ni los eventos que los inducen. En consecuencia, es adecuado iniciar un intento interdisciplinario por incorporar al análisis ambiental las particularidades de los momentos históricos, como por ejemplo, la apertu- ra y liberalización de la economía, la crisis cafetera y la violencia en el campo, que produce migración y desplazamiento.

Finalmente, este enfoque de análisis geográfico-ambiental expresa que los problemas ambientales urbanos ocasionados por población desplazada e inmigrante de bajos ingresos no se solucionan con propuestas exclusivamente técnicas (obras ingenieriles, saneamiento ambiental, reubicación de viviendas), pues es un hecho que la falta de atención y de soluciones reales a la problemática social del país y sus diferentes regiones son el motor de la invasión, ocupación, territorialización y posterior degradación y transformación ambiental de nuestros ecosistemas y gran biodiversidad.

\section{Bibliografía}

Alchldía de Pereira (2000): Plan de Ordenamiento Territorial de Pereira.

CARDER (2001): Ordenamiento territorial para el desarrollo sostenible en la ecorregión del eje cafetero. Pereira.

Coraggio, José Luis (1979): Sobre la espacialidad social y el concepto de región..

Delgado M., Ovidio (2000): Teorías sobre el espacio en la geografía contemporánea. Bogotá: Universidad Nacional de Colombia. Departamento de Geografía.

Empresas Públicas de Pereira (1993): Estudio hidrológico de los ríos Consota y Barbas.

Estebanez A., José (1994): Geografía Urbana-1. La dimensión espacial en el estudio de la ciudad. Madrid.

García Ballesteros, Aurora (1995): Geografía Urbana. La ciudad, objeto de estudio disciplinar.

284 Jorge Andrés Rivera Pabón 
(Coord) (1998): Métodos y técnicas cualitativas en geografía social. Barcelona: Oikos-tau.

Guariguata R., Manuel y G. Kattan H. (2002): Ecología y conservación de bosques neotropicales. LUR (Libro Universitario Regional), EULAC-GTZ.

IGAC (1988): Estudio general de suelos del departamento de Risaralda. Tomo I.

Jaramillo U., Jaime (1963): Historia de Pereira 1863-1963. Bogotá: Editorial Voluntad.

LABASSE, Jean (1979): La organización del espacio. Elementos de Geografía aplicada.

MonCAYo, Édgar (2001): Evolución de los paradigmas y modelos interpretativos del desarrollo regional. Bogotá: Universidad Nacional de Colombia. Red de Estudios de Espacio y Territorio, RET. Espacio y Territorios. Razón, pasión e imaginarios.

MontaÑez. G., Gustavo (2001): Introducción: razón y pasión del espacio y el territorio. Bogotá: Universidad Nacional de Colombia. Red de Estudios de Espacio y Territorio, RET. Espacio y Territorios. Razón, pasión e imaginarios.

Molano B., Joaquín (1990): Villa de Leyva. Ensayo de interpretación social de una catástrofe ecológica. Ed. Fondo FEN Colombia.

Ministerio del Medio Ambiente (1998): Bases ambientales para el ordenamiento territorial municipal en el marco de la ley 388. Guía para Corporaciones. Bogotá.

Parsons, James (1979): La colonización antioqueña en el occidente de Colombia. Bogotá: Carlos Valencia Editores.

SANABRIA, María Judith (1994): Caracterización limnológica de la cuenca del río Consota. Plan de saneamiento hídrico en el tramo urbano del municipio de Pereira.

SÁNCHEZ, Joan-Eugeni (1991): Espacio, economía y sociedad. Madrid: Siglo XXI.

Sánchez A., Ricardo (2002): Colección clásicos de Pereira. Alcaldía de Pereira 18751935. Núm. 2.

Santos, Milton (1990): Por una geografía nueva. Madrid: Espasa-Calpe.

(1996a): De la totalidad al lugar. Barcelona: Oikos-tau.

(1996b): Metamorfosis del espacio habitado. Barcelona: Iokos-tau.

Universidad del Valle, CARDER (1993): Aspectos biofísicos de los ríos Otún y Consota.

UCPR-CARDER (2003): Caracterización y diagnóstico del tramo urbano del río Consota en el municipio de Pereira.

Utr-Gtz (2004): "Proyecto Cambios ambientales en perspectiva histórica". Ecorregión del Eje cafetero, Volumen I. 
VIDART, Daniel (1986): Filosofía ambiental. Epistemología, praxiología, didáctica. Bogota: Editorial Nueva América.

Villota, Hugo (1999): Análisis de los atributos del paisaje en la zonificación ecológica. IGAC-CIAF.

(1991): Geomorfología aplicada a levantamientos edafológicos y zonificación física de las tierras. Bogotá: IGAC.

YeRenA, Édgar (2004): Corredores, ¿de qué estamos hablando? Venezuela: Universidad Simón Bolívar.

Fecha de recepción: febrero de 2005

Fecha de aprobación: abril de 2005

286 Jorge Andrés Rivera Pabón 